\title{
The current density of hydroxyapatite electrosynthesis by ion exchange resin chambers
}

\author{
Adrian Nur ${ }^{1, *}$, Nazriati Nazriati $^{2}$, Arif Jumari ${ }^{1}$, Ega Fitri Novita Santi ${ }^{1}$, and Shafira Yaumil Asiffa ${ }^{1}$ \\ ${ }^{1}$ Chemical Engineering Department, Faculty of Engineering, Sebelas Maret University, 57126 Surakarta, Indonesia \\ ${ }^{2}$ Chemistry Department, Faculty of Mathematics and Science, State University of Malang, 65111 Malang, Indonesia
}

\begin{abstract}
Electrochemical method has been developed to produce hydroxyapatite (HA) powders. Synthesis of hydroxyapatite particles was carried out from a homogeneous solution. The homogeneous solution was contained of $\mathrm{Na}_{2} \mathrm{H}_{2} \mathrm{EDTA} .2 \mathrm{H}_{2} \mathrm{O}, \mathrm{KH}_{2} \mathrm{PO}_{4}$ and $\mathrm{CaCl}_{2}$ on $0.25 / 0.25 / 0.15 \mathrm{M}$. Water reduction at cathode to form $\mathrm{OH}^{-}$ion is very substantial in formation of hydroxyapatite. The $\mathrm{OH}^{-}$ions causes the release of $\mathrm{Ca}^{2+}$ ions and change the equilibrium phosphate for the formation reaction of HA. The problem of electrochemical method is $\mathrm{OH}^{-}$ions move away from the cathode due to the difference in charge. This condition decrease the productivity of the formation of $\mathrm{HA}$ because $\mathrm{OH}^{-}$ions react with $\mathrm{H}^{+}$to form $\mathrm{H}_{2} \mathrm{O}$. In this work, we develop new method electrosynthesis of HA with 2 chambers system. The electrolysis use ion exchange resin to separate the $\mathrm{OH}^{-}$ions and $\mathrm{H}^{+}$ions formed. The effect of current density to HA product was studied. HA product analysed with XRD. We conclude that the electrosynthesis hydroxyapatite with ion exchange resin more effective than without ion exchange resin. The higher current density, the more pure HA formed.
\end{abstract}

\section{Introduction}

Hydroxyapatite, also called hydroxylapatite, is one of the calsium phosphate based bioceramic material which makes the majority of inorganic components of human bones and teeth. The formula of hydroxyapatite is $\mathrm{Ca}_{5}\left(\mathrm{PO}_{4}\right)_{3} \mathrm{OH}$ but usually written $\mathrm{Ca}_{10}\left(\mathrm{PO}_{4}\right)_{6}(\mathrm{OH})_{2}$ to denote that the crystal unit cell comprises two entities.

The calcium hydroxyapatite use as bone substitute materials because of their chemical similarity to the component of bones and teeth of mammalian. Calsium hydroxyapatite also used as fillers and coatings for repairing of large osseous defects [1].

Various synthesis methods have been used for powder hydroxyapatite synthesis, e.g. chemical precipitation method [2], hydrotermal technique [3. 4], emulsion method [5], and sol-gel process [6], mechanochemical method [7]. Chemical precipitation process is the most reported method for preparing hydroxyapatite particles. This process is simple, low cost, and suitable for industrial production but difficult to control and resultant particles have a low quality with a large particle size, wide particle size distribution and a lot of agglomerates. The hydrothermal technique usually gives hydroxyapatite powders a high degree of crystallinity. However, need high temperature and the obtained powders are usually in agglomeration and the size distribution are usually in wide range. The main advantage of emulsion technique is the simplicity of the process, good crystallinity product without high temperature, and favours the formation of small crystallites with a sufficient narrow size distribution. Sol-gel synthesis of hydroxyapatite has many advantages, which include high product purity, homogeneous composition, and low synthesis temperature. When the mass production of high crystalline hydroxyapatite is required, mechanochemical treatment is more suitable. Despite the risk of contamination during milling. Electrochemical deposition is one of the most commonly used method for hydroxyapatite coating at metal. This method is known to be the effective and efficient techniques to assemble fine particle. Reference [8] prepared nanosized powder hydroxyapatite using electrochemical method.

Electrochemical method has been successfully used for the synthesis of hydroxyapatite using constant direct current [9] and pulsed direct current [10]. The development process has also been successfully carried out with the use of EDTA as chelating agent.

References [11, 12] concluded that $\mathrm{OH}^{-}$ions produced by the reduction of water at the cathode was very substantial in the hydroxyapatite particles formation. The $\mathrm{OH}^{-}$ions caused the $\mathrm{Ca}^{2+}$ ion release from EDTA and the dissociation of phosphoric acid. This condition serve the reactants for particle formation. The problem is $\mathrm{OH}^{-}$ions move away from the cathode by diffusion and by migration. As a result, the formation of $\mathrm{HA}$ becomes ineffective because $\mathrm{OH}^{-}$ions formed is not fully utilized for the formation of HA.

In this work we have developed 2 chambers system with ion exchange resin to separate the anions $\left(\mathrm{H}^{+}\right.$ions) and cations $\left(\mathrm{OH}^{-}\right.$ions $)$. The novelty of this work is used

\footnotetext{
* Corresponding author: adriannur@staff.uns.ac.id
} 
2 chamber with ion exchange resin to electrosyntesis of hydroxyapatite. Selective cation exchange resin was installed around the cathode and selective anion exchange resin around the anode. Cation exchange resin prevent $\mathrm{OH}$ - ions migrate from the cathode while the anion exchange resin prevent the $\mathrm{H}^{+}$ions migrate to the cathode. The effect of current density to HA product was studied.

\section{Experimental}

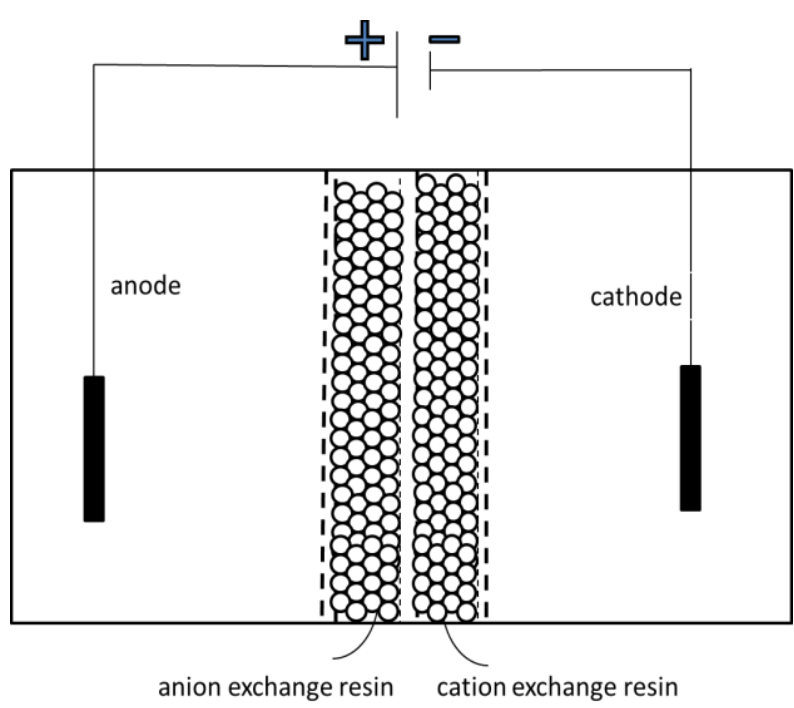

Fig. 1. A schematic presentation of electrochemical cell with ion exchange resin

The solution for the synthesis of HA powders was consisted of $\mathrm{Na}_{2} \mathrm{H}_{2}$ EDTA. $2 \mathrm{H}_{2} \mathrm{O}$ (Merck, reagent grade), $\mathrm{KH}_{2} \mathrm{PO}_{4}$ (Merck, reagent grade) and $\mathrm{CaCl}_{2}$ (Merck, reagent grade) with a concentration relationship of $\mathrm{Ca}^{2+} /$ EDTA/PO ${ }_{4}^{3-}$ as $0.25 / 0.25 / 0.15$ M. All chemicals were used as supplied with no further treatment. The electrolysis was carried out in a cell consisting of two carbon electrodes with dimensions of $(2 \times 1) \mathrm{cm}$. A simple two-compartment acrylic cell was used. The electrodes were set parallel with a distance of $3 \mathrm{~cm}$ between the electrodes and immersed in the solution at a depth of $2 \mathrm{~cm}$. The electrodes were connected to a DC power supply (Zhaoxin PS-3005D). The ion exchange resin chamber was installed between 2 electrodes (fig.1). The electrosynthesis was performed at 3 hours at 320 to $480 \mathrm{~mA} / \mathrm{cm}^{2}$ under constant stirring at room temperature. The suspension produced was filtered. The particle was washed with demineralized water and dried at $110^{\circ} \mathrm{C}$ for 2 days. The X-ray diffraction (XRD) pattern of the particles was detected using an X-ray diffractometer (Shimadzu 6000). The morphologies of the particles analysis were observed using scanning electron microscopy (Inspect S40, FEI). Fourier transform infrared spectroscopy (FTIR) (Shimadzu 8400s) was performed to evaluate the functional groups of specimens. The FTIR spectra were obtained over the region $500-4000 \mathrm{~cm}^{-1}$.

\section{Result and discussion}

The solution was clear at the beginning of the experiment when neither current nor potential had yet been imposed. As electrolysis, the surface of anode and cathode release the gas bubbles. The gas bubbles at anode indicate the formation of oxygen from oxidation of water. The gas bubbles at cathode indicate formation of hydrogen form reduction of water. A white precipitate was obtained.

$$
\begin{aligned}
& 2 \mathrm{H}_{2} \mathrm{O}+2 \mathrm{e}^{-} \rightarrow \mathrm{H}_{2(g)}+2 \mathrm{OH}^{-} \\
& 2 \mathrm{H}_{2} \mathrm{O} \rightarrow \mathrm{O}_{2(g)}+4 \mathrm{H}^{+}+4 \mathrm{e}^{-}
\end{aligned}
$$

The phase identification of powder was confirmed by FTIR spectroscopy. Comparison of FTIR spectra of particle with and without ion exchange resin is showed in Fig. 2. There is not significant different of FTIR spectra of particle with and without ion exchange resin. The spectra were collected in the 500 to $4000 \mathrm{~cm}^{-1}$ wavenumber range region. The FTIR spectra show that the phosphate and hydroxide absorption peaks for HA were seen. The characteristic bands for phosphate appear at $567 \mathrm{~cm}^{-1}, 603 \mathrm{~cm}^{-1}, 960 \mathrm{~cm}^{-1}$, and $1032 \mathrm{~cm}^{-1}$. The broad band of low intensity in the range $3000-3500 \mathrm{~cm}^{-1}$ can be attributed to traces of water incorporated to the structure, broad band around $1590 \mathrm{~cm}^{-1}$ of $\mathrm{H}-\mathrm{O}-\mathrm{H}$ bending mode. In the $\mathrm{OH}$ stretching vibration region, beside the $v \mathrm{OH}$ of the hydroxyapatite, surface $\mathrm{OH}$ band at $3500 \mathrm{~cm}^{-1}$ also appears.

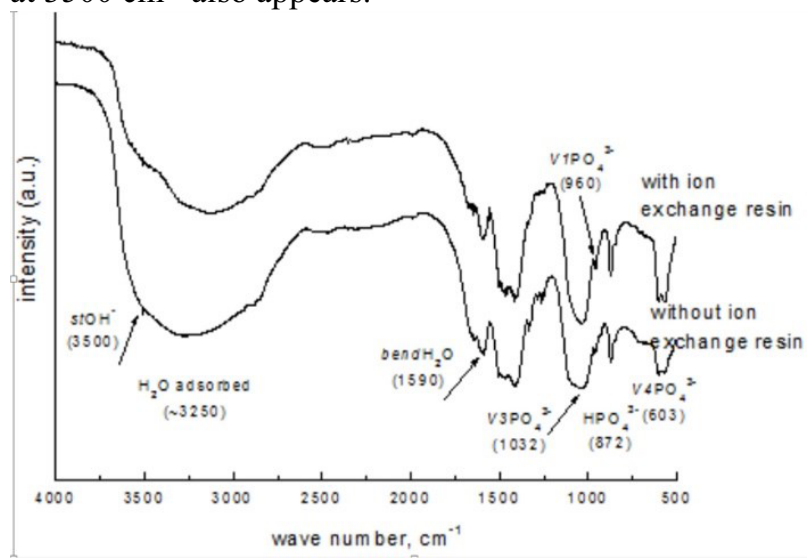

Fig. 2. FT-IR spectra of the HA particles with and without ion exchange resin

The morphology of powders with and without ion exchange resin at high magnification is provided in Fig. 3. The powder of HA without ion exchange resin consist of various shapes. The most of particles is cylinder-like shape. The powders with ion exchange resin consist of agglomerates which are composed of fine crystallites. The SEM micrograph of HA particles show that agglomeration of particles and spherical-like shape. The particles size is about 100 to $300 \mathrm{~nm}$. 


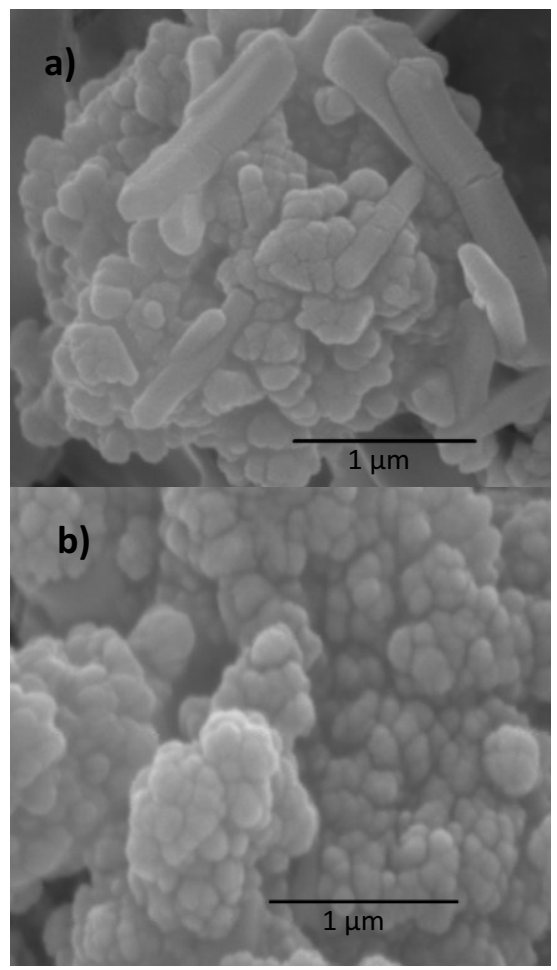

Fig.3. SEM images of the HA particles (a) without and (b) with ion exchange resin

Comparison of the particle with and without ion exchange resin was showed in Fig. 4. The electrosynthesis was performed at 3 hours at $1.5 \mathrm{~A}$ under constant stirring at room temperature. The XRD pattern of particle showed that the crystalline phase of particles with and without ion exchange was hydroxyapatite. There are 5 characteristic peaks at $25.9^{\circ}(002), 29.3^{\circ}$ (210), 31.6 $6^{\circ}(211), 32.2^{\circ}$ (300) and $34.1^{\circ}$ (202), which match the standard pattern of HA (JCPDS 09-0432). The XRD pattern of particle with ion exchange resin showed that the particle is pure HA, while without ion exchange resin showed they are another peaks. Another peaks for without ion exchange resin are $20.9^{\circ}$ and $30.5^{\circ}$ which match the standard pattern of brushite (JCPDS 720713). Brushite is the intermediate product which rapidly turned into HA. By the time when increase the $\mathrm{OH}^{-}$ion, the following reaction to take place

$\mathrm{Ca}^{2+}+\mathrm{HPO}_{4}^{2-} \leftrightarrow \mathrm{CaHPO} 4$

$10 \mathrm{CaHPO}_{4}+2 \mathrm{OH}^{-} \leftrightarrow \mathrm{Ca}_{10}\left(\mathrm{PO}_{4}\right)_{6}(\mathrm{OH})_{2}+4 \mathrm{PO}_{4}{ }^{3-}+10 \mathrm{H}^{+}$

This condition showed that electrosynthesis with ion exchange resin more effective than without ion exchange resin. The ion exchange resin separate electrochemical cell to 2 chambers. Cation exchange resin prevent $\mathrm{OH}^{-}$ ions migrate from the cathode while the anion exchange resin prevent the $\mathrm{H}^{+}$ions migrate to the cathode (Fig. 5). The formation of HA becomes more effective because $\mathrm{OH}^{-}$ions just formed HA particle.

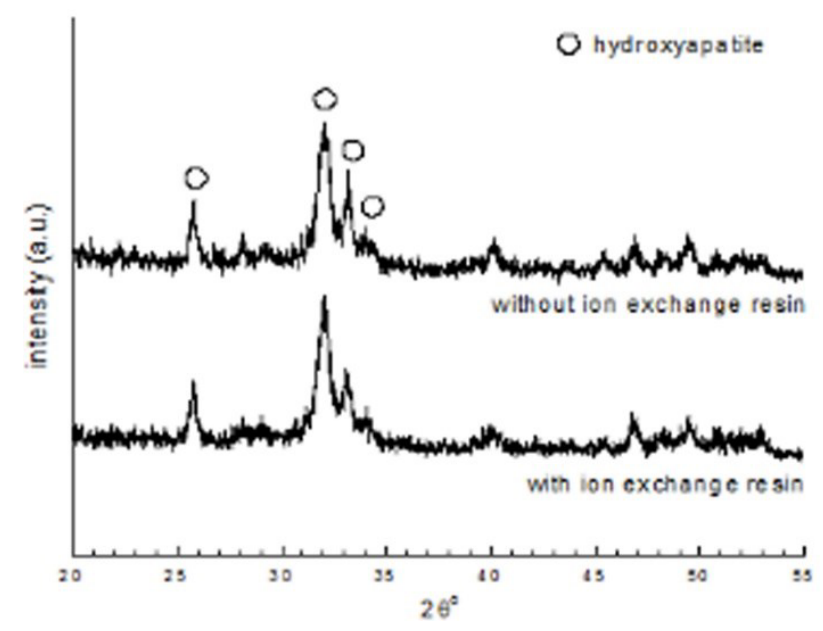

Fig.4. Comparison of XRD pattern of the HA particles with and without ion exchange resin

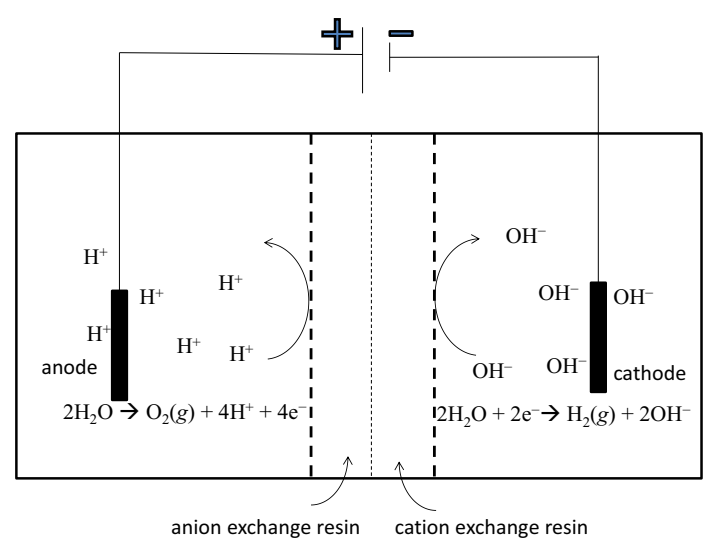

Fig.5. Electrochemical cell with Ion exchange resin

Observation of the solution $\mathrm{pH}$ is done all the time electrolysis. Fig.6. shows the solution $\mathrm{pH}$ for electrolysis time without resin and with resin (in anode and chatode chamber) (the smoothed line by B-spline). The solution $\mathrm{pH}$ without ion exchange resin decreases rapidly than the solution $\mathrm{pH}$ with ion exchange resin. As electrolysis, $\mathrm{OH}^{-}$ions were resulted by water reduction (Eq.1) and $\mathrm{H}^{+}$ions were resulted by water oxidation (Eq.2). According Eq.3, $\mathrm{OH}^{-}$ions react with brushite to form hydroxyapatite and release $\mathrm{H}^{+}$ions. The consumption of $\mathrm{OH}^{-}$ions and the release of $\mathrm{H}^{+}$ions causes the solution $\mathrm{pH}$ decrease.

The solution $\mathrm{pH}$ is very substantial to final product obtained. When the solution $\mathrm{pH}<7$, the final product is brushite and when the solution $\mathrm{pH}>7$, the final product is HA [14]. The maintaining of the solution $\mathrm{pH}$ above 7 during electrolysis is very essential to obtain HA. At electrolysis without ion exchange resin, the solution $\mathrm{pH}$ was 8 after 180 minutes and still obtain HA.

At electrolysis with ion exchange resin, there are two chambers i.e the anode and the cathode chamber. Fig.6. shows the solution $\mathrm{pH}$ in the anode and the cathode chamber for electrolysis time. In the anode chamber, the solution $\mathrm{pH}$ decreases by time electrolysis. The oxidation 
of water resulted $\mathrm{H}^{+}$ions (Eq.2.) due the solution $\mathrm{pH}$ decreases.

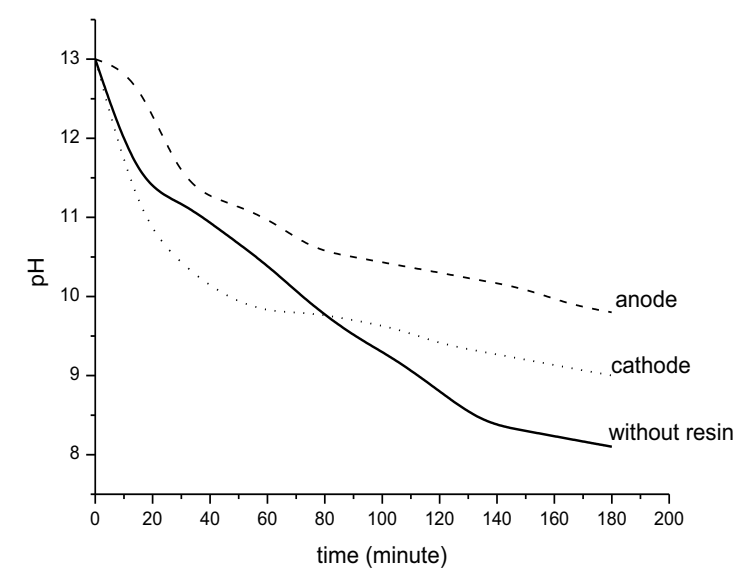

Fig.6. The solution $\mathrm{pH}$ for electrolysis time

In the cathode chamber, the reduction of water results $\mathrm{OH}^{-}$ions (Eq.1.). The $\mathrm{OH}^{-}$ions are consumed to form $\mathrm{HA}$ and resulted $\mathrm{H}^{+}$ions. The generation of $\mathrm{OH}^{-}$ions are smaller than the consumption of $\mathrm{OH}^{-}$ions. The solution $\mathrm{pH}$ in the cathode chamber decreases.

According observation of the solution $\mathrm{pH}$, the electrolysis with ion exchange resin more effective than without ion exchange resin. The solution $\mathrm{pH}$ for electrolysis with ion exchange resin decrease more slowly than without resin. Cation exchange resin prevent $\mathrm{OH}^{-}$ions migrate from the cathode.

Fig. 7 shows the XRD patterns of particles obtained at various the current density at $3 \mathrm{hrs}$. Hydroxyapatite was produced at the current density of 320 to $480 \mathrm{~mA} / \mathrm{cm}^{2}$. The peaks of hydroxyapatite phase increase in higher the current density. The higher current density, the more pure HA formed. The crystallite properties of the HA particles increase and the peaks of hydroxyapatite phase increase.

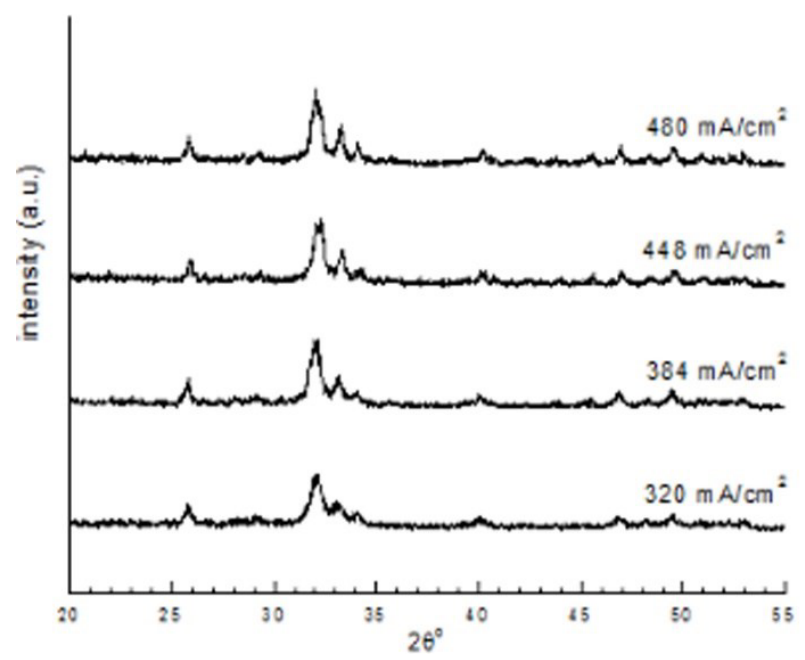

Fig.7. XRD patterns for particles prepared using various the current density
Fig.8. show the weight of precipitate at range of current density 320 to $416 \mathrm{~mA} / \mathrm{cm}^{2}$ for $3 \mathrm{hrs}$. At electrolysis without ion exchange resin, the weight of precipitate increase rapidly at 320 to $352 \mathrm{~mA} / \mathrm{cm}^{2}$. After current density $352 \mathrm{~mA} / \mathrm{cm}^{2}$, the weight of precipitate increase slowly and tend constant. The higher current density the more weight of precipitate. The higher current density increases the production rate of $\mathrm{OH}^{-}$ions. The higher concentration of $\mathrm{OH}^{-}$ions increases the production rate of precipitate.

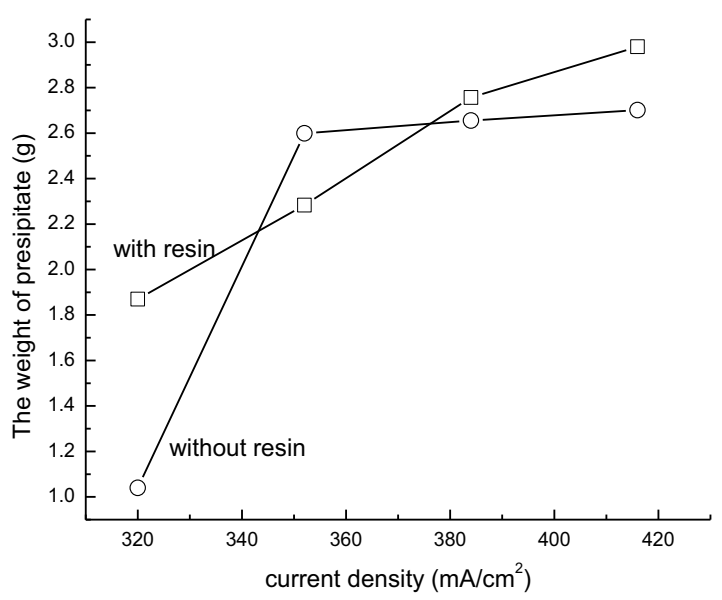

Fig.8. The weight of presipitate at various current density

At electrolysis with ion exchange resin, the weight of precipitate always increases at a range of current density 320 to $416 \mathrm{~mA} / \mathrm{cm}^{2}$. Generally, the weight of precipitate from the electrolysis with ion exchange resin higher than the electrolysis without ion exchange resin except at 352 $\mathrm{mA} / \mathrm{cm}^{2}$. According observation of the weight of precipitate, the electrolysis with ion exchange resin more effective than without ion exchange resin.

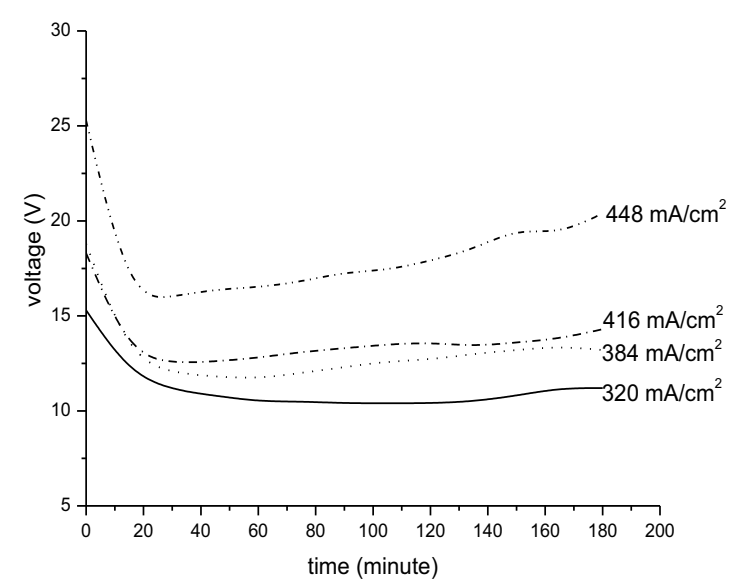

Fig.9. The applied voltage for electrolysis time 
The observation of the applied voltage at various of the current density for electrolysis time was done. The result of the observation was showed in Fig.9. The higher current density the higher applied voltage. The applied voltage decreases rapidly from 0 to about 20 minutes and increases after 20 minutes. For the constant current density, the applied voltage depends on the resistance between the anode and the cathode. The higher resistance the higher the applied voltage. In the first 20 minutes, the resistance decreases cause the applied voltage decrease. After 20 minutes, the particles between the both electrodes increase and the resistance increases.

\section{Conclusion}

The electrosynthesis hydroxyapatite with ion exchange resin more effective than without ion exchange resin. The ion exchange resin prevent $\mathrm{OH}^{-}$ions migrate to anion chamber. The formation of HA becomes more effective because $\mathrm{OH}^{-}$ions just formed HA particle. There is not significant different of XRD patterns of particles at various the current density.

The authors would like to thank for KEMENRISTEKDIKTI for Hibah Fundamental 2016.

\section{References}

1. S.V. Dorozhkin, Acta Biomaterialia 6 (2010) 715 734.

2. M.A. Martins, C. Santos, M.M. Almeida, and M.E.V. Costa, Journal of colloid and interface science, 318 (2008) 210-216.

3. M. Tomozawa, and S. Hiromoto, Acta Materialia, 59 (2011) 355-363.

4. R. Xin, F, Ren, and Y. Leng, Materials and Design 31 (2010) 1691-1694

5. A. Banerjee, A. Bandyopadhyay, and S. Bose, Materials Science and Engineering C, 27 (2007) 729-735.

6. M.H. Fathi and A.Hanifi, Materials Letters, 61 (2007) 3978-3983.

7. B. Nasiri-Tabrizi, P. Honarmandi, R. EbrahimiKahrizsangi, and P. Honarmandi, Materials Letters 63 (2009) 543-546.

8. M.S. Djosic, V.B. Miskovic-Stankovic, S. Milonjic, Z.M. Kacarevic-Popovic, N. Bibic, and J. Stojanovic, Materials Chemistry and Physics 111 (2008) 137-142.

9. A. Nur, D.L. Martasari, D. Nurwijayanti, S. Affandi, A. Widjaja, and H. Setyawan, Jurnal Teknik Kimia Indonesia, 11 (2013)

10. A. Nur, A. Rahmawati, N.I. Ilmi, S. Affandi, and A. Widjaja, AIP Conferensce Proceedings 1586(86) (2014)

11. A. Nur, H. Setyawan, A. Widjaja, and I. W. Lenggoro, Bulletin of Chemical Reaction Engineering \& Catalysis, 9(3) (2014) 168-175. 